\title{
STRUGGLING TO BREATHE: THE THORNY ROAD THAT SRI LANKAN COMMUNITY RADIO TRAVELLED THROUGH
}

\author{
Dr Ankuran Dutta \\ Associate Professor and Head, Department of Communication and Journalism, Gauhati University, \\ Gopinath Bordoloi Nagar, Jalukbari, Guwahati, Assam 781014, India. \\ K.G.L.A.N.S. Jayawardhana \\ Senior Lecturer, Department of Languages and Communication Studies, \\ Trincomalee Campus, Eastern University of Sri Lanka,
}

\begin{abstract}
Radio is considered as the most widespread electronic mass medium in the world and a unique means of reaching the world's poorest communities. However, as far as community radio (CR) is concerned, it addresses issues relevant to the public interest of a particular geographic group or community. It is the foremost medium that gives the marginalised a voice, when their voices are suppressed by the haves and the mainstream mass media which is also under the control of haves. The community radio in Sri Lanka has a four decade old history; yet, the country stands the risk of having this pioneering experience with CR locked away as a memory, as, of now, there is no community radio in true sense available in Sri Lanka. This paper has attempted to find out the reasons behind the failure of community radio broadcasting in Sri Lanka. Using semi-structured indepth interviews, eight leading community radio activists, advocates and researchers in Sri Lanka were interviewed. The causes identified for the failure of CR in Sri Lanka are state control over CR stations, an inexistent legal framework for community radio, inadequate funding, and human resources, misconceptions of responsible government authorities', the lack of knowledge about the true sense and relevance of community radio, the appointment of permanent staff from Sri Lanka Broadcasting Corporation than giving more priority to the volunteers from the same community, competition with mainstream media, and less dedication to community radio.
\end{abstract}

Keywords: Community Radio, Mainstream media, Sri Lanka Broadcasting Corporation, State Control, Community Ownership

\section{INTRODUCTION}

Community Radio, which is popularly known as the third tier of broadcasting, is the most vibrant communication tool among the marginalised communities. It gives a space to the information poor communities to address their voice poverty (Dutta, 2015). Community Radio services aid to motivate community participation in communication successfully, as well as to strengthen the cultural rights of a community (Rajapaksha, Rupasinghe, Nandasiri, 2014). In a democratic society, the mainstream broadcasting media, which includes both public service broadcasting and commercial broadcasting provides the free flow of information and voice opportunities (Selvaraj \& Kuppuswamy, 2017, p. 15; Bhatia, 2016, p. 58). However, these mainstream broadcasting media outlets precisely underrepresent the grassroots communities, which are left behind because of the poor access to the basic services, such as quality education, public health equality and other modern communication facilities (UNESCO, 2017).

Community radio is the most popular type of community media. Community media is one that is operated in the community, for the community, about the community and by the community (Dutta, 2019). As UNESCO (2018) defined, "Community media are characterized by their accountability to the communities they serve. They emerge as a result of popular movements that strive to attain an important space in citizen participation and demand the right to own and operate free from political or commercial interference." Community broadcasters are distinguished from public service and commercial broadcasters in as much as they are specifically tailored in their design and function to serve the voice and information needs of rural, grassroots and/or minority groups (UNESCO, 2017). 
In simple terms, the community drives the radio in every sense, be it production, management or ownership and communication for development was the core of community radio. According to Carter (2009), "One of the most common functions of community radio is to enable members of the community to voice their opinions, or to discuss and form common platform in dealing with various issues that may affect their common interests". Bruce Girard (1992) states there are five points to define community radio: community-based, independent, notfor-profit, for the community and participatory. Based on different literature and experiences, community radio can be defined as, "it is primarily a low power FM broadcasting service owned, controlled, managed and run by a particular community with a non-profit motive for providing and sharing information, education , and entertainment which may lead to eradicate digital divide, address identity crisis, remove socio-economic hindrance, promote local culture and resolve local issues resulting in overall development of a community (Dutta, Ray, 2014)."

Sri Lanka was the first South Asian country to do community broadcasting, starting with Mahaweli community radio (MCR) in 1981. Under the Mahaweli Project (1978-1987), 1 million displaced and landless people were resettled in mainly agricultural zones (Weerasinghe, 2011, p. 127). "Community radio is a relatively recent phenomenon in South Asia, in comparison to other parts of the world" (Seneviratne, 2012). In developing countries, community radio has a developmental mission and sees itself as uniting either geographical communities or communities of interest around common economic, cultural, or linguistic interests and themes. Community radio is now widely recognised, both by governments and the international development community, as the "third-tier" of broadcasting, with the first being state/public broadcasting and the second being commercial broadcasting.

The primary research question was to access why the community radio in Sri Lanka could not become a sustainable and successful grassroots communication tool despite of the pioneering efforts initiated in Sri Lanka for the first time in South Asia.
Status of Community Radio in Sri Lanka

Sri Lanka has been a pioneer in experimenting with community radio in the South Asian region, inspiring activism and movements for independent community radio among her neighbours across the Indian Ocean. The history of community radio or community broadcasting in Sri Lanka can be categorised into two phases. The first phase is 'the community-oriented broadcasting'. In this phase, the broadcasters of the Sri Lanka Broadcasting Corporation (SLBC) who were working at Kandy Regional Center, visited Mahaweli resettled villages to meet villagers and discussed their problems, recorded the needed voice-cuts, came back to the regional radio station, produced radio programmes on the issues faced by the resettled villagers and broadcasted them to the people via SLBC frequencies. The second phase is 'establishing radio in the community in 1986. Local, low powered community radio stations were set up in this phase. It reduced the time and the cost to travel from the regional station to rural villages. Broadcasters were able to spend much time with the villagers to produce fruitful programmes as a result of establishing community radio stations where the community resided.

When studying the four decades of community radio history in Sri Lanka, nine community radio stations were identified. The oldest among them was Mahaweli Community Radio (MCR), established in 1981. Other sister community radio stations can be listed chronologically as Girandurukotte Community Radio (1986), Mahailuppallama Community Radio(1987), Kothmale Community Radio (1989), Pulathisi Rawaya Community Radio (1995), Uva Community Radio (2003), SARU Community Radio (VSHLI Community Radio) (2005), Dambadeniya Community Radio (2007) and Dambana Community Radio(2012).

Mahaweli Community Radio (MCR) was the first community radio experiment in Sri Lanka introduced in 1981. "MCR was the result of a large development scheme initiated by the government of Sri Lanka in 1979 to divert the country's longest river Mahaweli and build a number of dams. People uprooted from their lands and settled in a totally different geographical area needed development communication to rebuild their lives and that 
is where MCR came into existence with the support of UNESCO and DANIDA - the Danish Development Aid Agency" (Seneviratne, 2012). One of the major experiments of Mahaweli community radio conducted in community radio in Asia was, to establish localised community radio stations that are semi-autonomous small community radio stations with social and geographical proximity to the listeners.

But, at the end of the day, when the project was completed and the external funding dried out, it negatively affected the survival of the community radio which started as one of the prime features of the particular development scheme. While, Mahaweli community radio was taking its last breath, in 1986 the situation paved the path to the establishment of the first local community radio station called Girandurukotte Community Radio. The condition of Girandurukotte was very serious as the radio station was caught in between the government schedules and a rebellion that started from a militant youth during 1988-89 in Sri Lanka. The success of the Mahaweli Community Radio had largely been the overwhelming response in terms of listenership as well as active participation (Karunanayake, 2016).

Mahailluppallama Community Radio was established in 1987 in Mahailluppallama (Mahaweli System H.) followed by Girandurukotte Community Radio. "People in the community believed that Mahailluppalama $C R$ is the voice for the grassroots lived in Mahailluppallama area and it is a part of them" (Wijesinghe, 2018).

The first radio programme of Kothmale Community Radio (KCR) was transmitted in February, 1989 by Sri Lanka Broadcasting Corporation. "KCR was created in response to a development scheme by the Mahaweli Authority, which displaced over 2,900 families, some 60,000 people, in order to build Sri Lanka's second-largest dam project" (Carter, 2009).

Pulathisi Rawaya Community Radio (1995) was established under the control of SLBC to build peace in the remote North Central and Eastern regions. It also was maintained by the Mahaweli Development Authority. It functioned till 2002, and terminated without any known legitimate reason.

Kothmale Community Radio station is located in the central hill region of Sri Lanka, and serves a population of 200,000 people. Sixty villages (with an average population of 400 each) and three rural towns (Navalapitiya, pop. 64,000; Gampola, pop. 56,000; and Hatton, pop. 54,000) are located within the radio station's target area (Jayaweera, 2001).

Uva Community Radio (UCR) (2002) which broadcasts their programme even today is a landmark in the community radio history in Sri Lanka. UCR was planned as an integral part of the Uva Area Based Growth and Equity Programme implemented by UNDP Colombo. "With the vision of 'an independent voice devoid of controls, for the voiceless, diverse communities", "SARU" community radio came into existence in 2005 under the Gemidiriya Community Development and Livelihood Improvement Project funded by the World Bank, launched in Polonnaruwa, which later on covered more than 1,000 villagers" (Swarnalatha \& Batuwitage, 2012). Its frequent broadcasting has been disturbed due to nonissuance of a license to operate the radio. Although, years ago, Gemidiriya communities have applied for a license and frequency for their community radio, they haven't received a positive feedback from the government.

Dambadeniya Community Radio has been initiated by Dambadeniya Development Foundation, with the assistance of One World South Asia, and was inaugurated on July 9, 2007. The primary objective is to fill the communication gaps existing in all the levels of the particular community. It is situated at Rammuthugala, Narammala in Sri Lanka. The youth, women and school-going children of Dambadeniya export-village took the initiative to establish Dambadeniya Community Radio. Dambana radio was established in 2012 by SLBC in the place of Girandurukotte to cater to the Vedda Community. The chief consultant for the radio is Vedda Community leader (Currently, Uruwarige Wannile Aththo). The target audience of this radio station was Vedda indigenous community of Sri Lanka.

Community Radio is considered as the most accessible and the most suitable medium for a rural community, as it doesn't require literacy 
to access it. Most importantly, community radio is a kind of binding force of the community that leads to a better livelihood. When studying the pathway of Community Radio in Sri Lanka, it can be seen that community radio has gained some of the early successes. Community radio created a platform to the voiceless to raise their voice and finding out the solutions for their burning issues. Being an independent entity, community radio was addressing the hearts of the listeners while the state broadcasters function on their own agenda importantly focusing on the political and financial benefits.

\section{METHODOLOGY}

The researchers have used both primary and secondary methods of data collection. In-depth interview was used as the primary data collection method and the secondary data were collected through books, magazines, newspapers, dissertations and electronic sources. The researchers selected in-depth interviews as the primary data collection method because this study was highly dependent on the experiences, opinions and suggestions of the prominent community radio activists in Sri Lanka to have a detailed understanding about the true reasons that laid behind the failure of CR in Sri Lanka. In this study, the researchers purposively selected eight respondents depending on the two community radio eras in Sri Lanka, four each from the first phase of community radio broadcasting and four from the second phase of community radio broadcasting.

The data analysis was done by using Glaser's Constant Comparative Method. Using this method, the respondents' responses were compared to each other (using what have been written down in transcripts) and categorised them under different topics such as state control, insufficient funding, no legal/ policy framework etc), to find the reasons for the failure of community radio in Sri Lanka.

\section{FINDINGS}

To fulfill the objective of the study, the respondents were interviewed in order to identify the reasons for the failure of community radio in Sri Lanka. According to the answers they provided, the researchers found the following factors as major reasons for the failure of CR in Sri Lanka.
Lack of Community Ownership:

Community ownership is the first and foremost feature of a community radio. Unfortunately, there was no community ownership on the transmitters of the radio stations (Senanayake, 2007).

State Control over Community Radio stations The principal cause while studying the reasons for the failure of community radio in Sri Lanka is the excessive control of the community radio stations by the government. The Sri Lanka Broadcasting Corporation (SLBC) is a government broadcasting institution. Hence, broadcasters and what they broadcast were nothing more than rural transmissions of the fully state-owned and state-controlled Sri Lanka Broadcasting Corporation. The bureaucracy in Colombo tightly controlled content: nothing remotely critical of the government in office was permitted. In order to make sure the CR functions in favour of the government, SLBC appointed its employees to handle CR.

\section{No Legal framework for community radio -}

"There is no direct law or policy available in Sri Lanka with community radio. Not even a reference made on any sort of radio that operates from the village level" (Rasmin, 2017). In Sri Lanka, so far licenses for broadcasting radio and TV are issued only to the government and corporate sector, not for community-owned community broadcasting. The broadcasting of "SARU" community radio has been disturbed without a license to run the radio. Although, years ago, Gemidiriya communities had applied for a license and a frequency for their community radio, yet, they haven't received any positive feedback from the government because there is no policy framework which has been particularly designed for CR in Sri Lanka.

Insufficient funding - Once UNESCO and DANIDA withdrew from providing financial support for community radio in 1984, SLBC had to take the responsibility of maintaining the community radio. It became an extra burden on SLBC. Moreover, community radio broadcasters too, weren't decided on any plan and strategy to build up their financial stability and stand alone. Therefore, SLBC took the necessary steps to close down the CRs, instead of giving responsibility and the 
independence to community radio stations to flourish themselves.

\section{Lack of conceptual clarity of State:} Responsible government authorities' misconceptions and the lack of knowledge about the true sense of community radio - The relevant authorities didn't realize community radio in true sense. The authorities were questioning the need for having community radio stations, while there are few regional radio stations to cover the media's dark areas in Sri Lanka. Also, there was a misconception among the government authorities that making community radio free from their control could be a threat to the political stability and security of the country.

Lack of Freedom: Appointing a permanent staff from SLBC was given more priority than to the volunteers from the same communitySLBC appointed their employees to handle CR stations; especially, the appointed station managers were SLBC employees. Administrative power was in the hands of SLBC and the community representatives participated as only producers and anchors. "The whole exercise of CR in Sri Lanka was practiced within the framework of SLBC" (David, 2017). Hence, many of the permanent staff members who were appointed and joined the community radio stations didn't have a proper sense about the true community radio, its role, and the target community. They considered their appointment to the community radio as just another phase of their job. Many of them merely worked for the remuneration they received from SLBC.

\section{Competition with mainstream media -} Mainstream media were also a challenge for community radio. Mainstream media began to use two-way communication and participatory communication effectively, as part of their strategy, which used to be the domain or competitive advantage of community radio broadcasting. When community radio were seeking financial support from the community for its survival, private radio stations had started giving cash prizes to their listeners through different programmes in order to attract and increase their listenership. Private radio channels strategically motivated their listeners to listen to their channels. That was a real challenge faced by community radio at that time. FM channels bulldoze the subcultures where the real identity of Sri Lankan culture secures instead of facilitating them and creating a platform for media-literate citizens.

Lack of dedicated human resources: - SLBC faced many difficulties when recruiting the staff for CR stations. The number of experienced radio producers who applied for the posts in CR was very few and many of them had come forward to do so just to get their promotion. SLBC had managed to fill the basic cadre with operational assistants who liked to be producers and new recruits who were fresh university graduates. Today in Sri Lanka, only Uva community radio maintains its regular broadcasting as it has a permanent staff to run the radio because Uva provincial council has hired them on a monthly salary basis. But, the problem with "SARU" community radio is, it is not financially stable to hire their own permanent staff, hence, many only volunteer in SARU, but, engage with other means of living.

Based on the above findings, diagnosing the reasons for the failure of community broadcasting in Sri Lanka and initiating the needful to bring community radio back to life will be facilitated. Community radio is not the medium moving into the community rather the community moving into the medium. Apart from the community ownership, participatory communication and operation as a non- profit entity, its horizontality and diversity double its worth of existence. The time has come to identify the missing link and create the platform to restore the "voice of the voiceless", the community radio in the true sense in the Sri Lankan context.

\section{CONCLUSION}

Community radio is the only medium in a developing nation that facilitates proper representation and participation of people in development, addresses the unmet needs of communities pertaining to - job opportunities, vocational training and also facilitates in having responsible and accountable citizens (Senanayake, 2007). The community radio broadcasting in Sri Lanka which began in 1981 has passed many milestones in its journey while facing a number of challenges. But, they were playing a memorable role by empowering grassroots with the needed 
information \& knowledge and by working very close to them for the betterment of particular target communities. Unfortunately, after struggling for more than three decades, by now, the community radio has shed the last drop of sweat to make sure their existence in Sri Lanka, but, they have failed. By now, there is no properly functioning "community radio" in real sense in Sri Lanka.

The initial steps to establish community radio in Sri Lanka were taken by the government of Sri Lanka. The government had realised the fruitfulness and the applicability of CR in Sri Lankan context to empower the marginalised people. But, later, the response and the way the government treated community radio was extremely negative and unfavourable. By knowing community radio stations' struggle to breathe, the government didn't positively react to form a proper legal framework to protect and facilitate the smooth functioning of community radio in Sri Lanka.

Owing to the current situation, the country stands the risk of having the pioneering experience of $\mathrm{CR}$ among the South Asian countries going to be locked away as a memory, unless efforts towards its revival are made by finding out the actual reasons that lay behind the failure of community broadcasting in Sri Lanka. After so many years of community broadcasting, even today, the listeners, community broadcasters or the majority of programme makers and even theoreticians and other interested persons in Sri Lanka are unable to conceptualise correctly a genuine community radio.

It is crucial to understand the need to revive community radio stations in Sri Lanka because, they facilitate proper representation and participation of people in development, address the unmet needs of communities pertaining to job opportunities, vocational training, facilitate in having responsible and accountable citizens, and providing new ways of entertainment. This is where community radio has great potential, particularly, because it helps bottom up decision making from each and every community in the decentralised administration. Therefore, community radio facilitates the process of democratic and true nation building.
Hence, finding out the reasons for the failure of community broadcasting in Sri Lanka will pave the path to ascertain the possible solutions to restore and uplift community broadcasting in Sri Lanka.

\section{REFERENCES}

Bhatia, C. (2016). Democratizing the rural development in India: A Case Study of Radio Mewat. Journal of Content, Community \& Communication, 4(2), 5865. https://www.amity.edu/gwalior/jccc /democratizing\%20the\%20rural $\% 20$ devel opment $\% 20$ in $\% 20$ india-

a\%20case $\% 20$ study $\% 20$ of $\% 20$ radio $\% 20$ me wat.pdf

Carter, L. H. (2009). Kothmale community radio interore project: True community radio or feel - good propaganda, International review of research in open and distance learning, volume 10.

Dutta, A. (2015, February 26). Community Radio Across South Asia- Understanding its Potential in Adrressing Voice Poverty. Commonwealth Educational Media Centre for

Asia. https://www.slideshare.net/CEM CA/cr-south-asia-colombo

Dutta, A. (2019, January 24). Defining Community Radio. Community Communications. Retrieved March 16, 2020,

from https://www.comcomm.org/2019/ 01/defining-community-radio.html

Dutta, A., \& Ray, A. (2014, October 12). Defining 'Community'. Community Communications. Retrieved March 16, 2020, from https://www.comcomm.org/2014 $\angle 10 /$ defining-community.html

Girard, B. (1992). A Passion for radio: radio waves and community. Black Rose Books.

Girard,B. (2001). A passion for radio: radio waves and community, electronic edition version, published by Bruce Girad \& Comunica retrieved from http://www.comunica.org/passion/

Herath, D.B. (2015). the role of the indigenous radio today and its impact on the audience: the case of Dambana FM in Sri Lanka, International Journal of 
Humanities and Social Sciences, World Academy of Science, Engineering and Technology, Vol:9,No.8, Netherlands.

Jayaratne,T. (2012). Sri Lanka's struggle to establish community radio, Peoples' voices, Peoples' empowerment: community radio in Asia and beyond, $1^{\text {st }}$ edition, p.g.52 Nanyang Technological University, Singapore.

Jayaweera, W. (2001, June 8). Kothmale Community Radio/Internet Project: Expanding the Knowledge Base. World Bank

https://siteresources.worldbank.org/IN TEGOVERNMENT/Resources/7024781129947675846/kothmale_cs.htm

Karunanayake, N. (1986) The Mahaweli Community Radio in Sri Lanka: A Promising Experiment, Media Asia, 13:4, 209-214,

DOI: $\underline{10.1080 / 01296612.1986 .11726231}$

Orusolvasagan, R., Chandru,V., \& G, Dalin. (2017). Community radio a social tool for women empowerment in Namakkal District, International journal of emerging trends in science and Technology, Vol.04, Issue.08, ISSn.23489480, India.

Rajapaksha, S., Rupasinghe, W., Nandasiri, A. U. (2014). The Problem Related with Community Radio Concept \& Restarting of Community Radio in Sri Lanka. Global Communication Research Association (GCRA) 2014 International Conference on Media in Transformation: Exploring Role of ICT, Innovation Communication \& New Media. 14th to 16th February 2014. Colombo, Sri Lanka. Abstracts. P.17

Rasmin, M. C. (2017). Need for community ownership and legal recognition: Community radio in Sri Lanka, paper presented at International Conference, IAMCR, UK
Selvaraj, M., \& Kuppuswamy, S. (2017). Peridar Kaala Vaanoli: Social Utility \& Linkage with Cuddalore Community. Journal of Content, Community \& Communication, 5(3), 1521. https://www.amity.edu/gwalior/jccc /jcc_journal_june_2017_06092017.pdf

Senanayake, D. (2007, August 1). Bringing back the missing link in community radios in Sri Lanka - voices of community. Practical Action. Retrieved March 20, 2020, from http://communityradio.in/pdf/commu nity-radios-in-sri-lanka.pdf

Seneviratne,K. (2012). Community radio in Asia: Slowly coming out of the shadows, Peoples' voices, and Peoples' empowerment: community radio in Asia and beyond, $1^{\text {st }}$ edition, Nanyand Technological University, Singapore.

Swarnalatha, R. M. S. \& Batuwitage, G. (2012). A Sri Lankan experiment: Community driven radio for livelihood improvement, Peoples' voices, Peoples' empowerment: community radio in Asia and beyond, $1^{\text {st }}$ edition, Nanyang Technological University, Singapore.

UNESCO. (2017, November 23). UNESCO Community Media Sustainability Policy Series. Retrieved March 19, 2020, from https://en.unesco.org/community -media-sustainability/policyseries/defining

UNESCO. (2018, January 3). Community Media. Kenya National Commission for UNESCO - Service to Kenya and UNESCO. Retrieved March 19, 2020, from https://unesco.go.ke/programme /community-media/

Weerasinghe, P. N. (2011). Community Radio (Sri Lanka) Pradeep N'. In J. D. Downing(Ed.), Encyclopedia of Social Movement Media (pp. 127-129). SAGE. 